Arq. Bras. Med. Vet. Zootec., v.69, n.2, p.381-390, 2017

\title{
Comportamento ingestivo e parâmetros sanguíneos em ovinos que receberam dietas contendo aditivos à base de extratos de própolis em pó
}

\author{
[Ingestive behavior and blood profile in sheep fed with diets containing powdered \\ propolis extract additives] \\ O.P. Prado-Calixto ${ }^{1}$, I.Y. Mizubuti ${ }^{1}$, E.L. A. Ribeiro ${ }^{1}$, E.S. Pereira ${ }^{2}$, R.T. Silva ${ }^{3}$, N.L. Corletto ${ }^{3}$, \\ E.L.T. Peixoto ${ }^{4}$, L.N. Carvalho ${ }^{5}$, A.K. Nihei ${ }^{5}$, F.L. Massaro Júnior ${ }^{1}$, \\ L.D.F. Silva ${ }^{1}$, S. Galbeiro ${ }^{1}$ \\ ${ }^{1}$ Universidade Estadual de Londrina - UEL - Londrina, PR \\ ${ }^{2}$ Universidade Federal do Ceará - UFC - Fortaleza, CE \\ ${ }^{3}$ Aluno de pós-graduação - Universidade Estadual de Londrina - UEL - Londrina, PR \\ ${ }^{4}$ Universidade Federal do Sul e Sudeste do Pará - Unifesspa - Marabá, PA \\ ${ }^{5}$ Alunos de graduação - Universidade Estadual de Londrina - UEL - Londrina, PR
}

\begin{abstract}
RESUMO
Objetivou-se avaliar os efeitos do extrato de própolis (LLOSC2) sobre o comportamento ingestivo e os parâmetros sanguíneos em cordeiros alimentados com dieta concentrada. Foram utilizados quatro cordeiros machos, castrados, sem raça definida e com peso médio inicial de $32 \pm 1,92 \mathrm{~kg}$, mantidos em gaiolas metabólicas individuais durante todo o período experimental. O delineamento experimental foi em quadrado latino $4 \times 4$, com quatro animais, quatro dietas e quatro períodos experimentais. As dietas diferiram em relação à adição ou não de extratos de própolis à ração. As dietas testadas diferiam na adição de zero (controle), $1(88,16 \mathrm{mg} / \mathrm{g}$ de flavonoides), duas $(176,32 \mathrm{mg} / \mathrm{g}$ de flavonoides) ou três $(264,48 \mathrm{mg} / \mathrm{g}$ de flavonoides) doses de aditivo à base de extrato de própolis LLOSC2. A dieta tinha relação volumoso:concentrado de 40:60 e foi formulada para ganhos de $250 \mathrm{~g}$. A ração concentrada era composta de milho e farelo de soja. O comportamento ingestivo dos animais foi observado por 24 horas, divididas em quatro períodos de seis horas. As coletas de sangue eram realizadas no último dia do período. Não houve efeito das doses LLOSC2 sobre o tempo despendido em alimentação, ruminação, ócio e ingestão de água. A duração do ciclo ruminativo foi maior nos animais que receberam duas doses de LLOSC2, e o número de movimentos mastigatórios também tendeu a aumentar no período que compreendia das 13 às 19h. Já a dieta contendo uma dose de LLOSC2 aumentou a duração da ruminação do bolo bem como o seu número total de mastigações no período de uma a sete horas. Houve uma diminuição nos níveis séricos de cortisol com a adição de três doses de LLOSC2. O hemograma, o leucograma, o perfil bioquímico e as imunoglobulinas não foram afetados pela inclusão das doses de LLSOC2. A administração de extrato de própolis LLOSC2 à dieta de ovinos não afetou seu comportamento ingestivo, os parâmetros hematológicos, bioquímicos e imunológicos estudados.
\end{abstract}

Palavras-chave: cortisol, parâmetros hematológicos, parâmetros imunológicos, perfil bioquímico, ruminação

\begin{abstract}
The objective of this study was to evaluate the effects of propolis extract (LLOS 2) on feeding behavior and blood parameters in lambs fed concentrate diet. Four male lambs were castrated, mongrel and average weight of $32 \pm 1.92 \mathrm{~kg}$, kept in individual metabolic cages throughout the trial period. The experimental design was a Latin square $4 \times 4$ with four animals, four treatments and four experimental periods. The diets differed according to addition or not of propolis extracts to feed. The experimental diets differed in addition to zero (control), 1 (88.16mg/g flavonoids) 2 (176.32mg/g flavonoids) or 3 (264.48mg/g flavonoids) Additive doses based on LLOSC2 propolis extract. The diet had a
\end{abstract}

Recebido em 7 de julho de 2016

Aceito em 9 de julho de 2016

E-mail: odimari@uel.br 
forage:concentrate ratio of 40:60 and was formulated to $250 \mathrm{~g}$ gains. The concentrate ration was composed based on corn and soybean meal. The feeding behavior of the animals were observed for 24 hours, divided into four periods of 6 hours. Blood collections were made on the last day of the period. There was no effect of LLOSC2 doses on time spent eating, ruminating, leisure and water intake. The duration of the ruminative cycle was higher in animals that received two doses of LLOSC2 and the number of chewing movements also tended to increase in the period comprised from 13 to 19h. Since the diet containing a dose of LLOSC2, increased duration of rumination cake as well as its total number of chewing in the period of 1 to 7 hours. There was a decrease in serum cortisol with the addition of three doses of LLOSC2. The blood count, white blood cell count, biochemical profile and immunoglobulins were not affected by the inclusion of doses of LLSOC2. Administration of LLOSC2 propolis extract the sheep diet did not affect their feeding behavior, hematological, biochemical and immunological studies.

Keywords: biochemical profile, cortisol, hematological parameters, immunological parameters, rumination

\section{INTRODUÇÃO}

Aditivo alimentar ou aditivo para produtos destinados à alimentação animal são definidos pelo Ministério da Agricultura, Pecuária e Abastecimento (IN 13/04) como "substância, micro-organismo ou produto formulado, adicionado intencionalmente aos produtos, que não é utilizado normalmente como ingrediente, tenha ou não valor nutritivo e que melhore as características dos produtos destinados à alimentação animal e dos produtos animais, melhore o desempenho dos animais sadios ou atenda às necessidades nutricionais". Os aditivos são classificados como tecnológicos, sensoriais, nutricionais e zootécnicos (Brasil, 2004).

O objetivo do emprego de aditivos alimentares nutricionais na alimentação animal é melhorar a conversão alimentar e a eficiência da utilização da energia metabolizável, com possível redução nos custos com a alimentação e o aprimoramento no desempenho.

Os aditivos químicos têm sido as substâncias mais empregadas com esse fim. Contudo, sua utilização pode estar relacionada com a seleção de cepas bacterianas resistentes (Andreotti e Nicodemo, 2004) e representar um risco à saúde humana. Portanto, a União Europeia (UE) proibiu o uso desses aditivos na alimentação animal (Resolução EU 1831/2003).

Assim, a busca de aditivos alimentares nutricionais alternativos se faz necessária e o extrato de própolis é uma opção na nutrição de ruminantes, visto que foram observados menores valores de produção de gás in vitro, indícios de menor produção de metano e maior aproveitamento da dieta (Leopoldino et al., 2007). Entretanto, existem poucas informações em relação aos efeitos da própolis sobre o comportamento ingestivo do animal, que é parâmetro importante na nutrição, pois possibilita o ajuste do manejo alimentar para melhorar o desempenho produtivo (Mendonça et al., 2004).

O estresse pode estar relacionado com menores índices produtivos. Uma maneira de se constatar se as condições às quais os animais estão sendo submetidos lhes proporcionam bem-estar é por meio da dosagem de cortisol sérico (Smith et al., 1996). Condições estressantes também podem levar a outras alterações hematológicas. Portanto, a análise sanguínea é importante, uma vez que fornece informações a respeito da reação do organismo frente a microrganismos patogênicos e a carências nutricionais (Guerci, 1985).

Deste modo, o objetivo do presente estudo foi avaliar os efeitos da adição de doses crescentes de extrato de própolis LLOSC2 na ração concentrada sobre o comportamento ingestivo e os parâmetros sanguíneos de cordeiros.

\section{MATERIAL E MÉTODOS}

O experimento foi conduzido no setor de Metabolismo de Ruminantes, na Fazenda Escola da Universidade Estadual de Londrina, e seus procedimentos experimentais foram previamente aprovados pela Comissão de Ética no Uso de Animais da Universidade Estadual de Londrina, sob o ofício circular Ceua $n^{\circ} 123 / 2013$. Foram utilizados quatro ovinos machos, castrados, sem raça definida, com peso vivo médio de $32 \pm 1,92 \mathrm{~kg}$. Os animais foram distribuídos 
aleatoriamente e alojados em gaiolas metabólicas individuais providas de bebedouro e comedouro, durante todo o período experimental.

O delineamento experimental foi em quadrado latino $4 \times 4$, compreendendo quatro animais, quatro períodos e quatro dietas. As dietas diferiram em relação à adição ou não de extratos de própolis na ração, sendo uma dieta sem adição de própolis (controle) e dietas com uma, duas e três doses de produto à base de própolis LLOSC2.

$\mathrm{O}$ aditivo à base de extrato de própolis em pó LLOSC2 (registro no Instituto Nacional de Propriedade Industrial $\mathrm{n}^{0}$ 0605768-3) foi preparado na Universidade Estadual de Maringá (UEM). A própolis verde foi obtida no apiário orgânico da UEM, formado por colônias de abelhas africanizadas (Apis mellifera). $\mathrm{O}$ apiário está localizado em uma reserva de eucalipto (Eucalyptus sp.), cercado por mata nativa, com a presença de alecrim-do-campo (Baccharis dracunculifolia).

O extrato de própolis foi obtido por meio de extração turbo durante 15 minutos, com concentração de própolis $\mathrm{C}$ e teor alcoólico 2 . Em seguida, o extrato foi filtrado a vácuo, submetido à desalcoolização em evaporador rotativo (Buchi, modelo TA 210), submetido ao processo de secagem por pulverização (Nebulizador Labmaq, modelo MSD 1), e o produto obtido foi incorporado ao veículo fubá de milho (50:50). As concentrações de flavonoides e ácidos fenólicos contidas nas dosagens de aditivo LLOSC2 foram determinadas por cromatografia líquida de alta eficiência (Tab. 1).

Tabela 1. Concentração de componentes nas dosagens utilizadas de aditivo à base de extrato de própolis $\operatorname{LLOSC}^{1}$

\begin{tabular}{lcc}
\hline LLOSC2 & Flavonoides $\left(\mathrm{mg} \mathrm{g}^{-1}\right)^{2}$ & Ácidos fenólicos totais $\left(\mathrm{mg} \mathrm{g}^{-1}\right)^{3}$ \\
\hline 1 dose & 88,16 & 30,94 \\
2 doses & 176,32 & 61,88 \\
3 doses & 264,48 & 92,82 \\
\hline
\end{tabular}

${ }^{1}$ Aditivo à base de extrato de própolis; ${ }^{2}$ concentração média de flavonoides quantificados em apigenina; ${ }^{3}$ concentração média da soma dos ácidos fenólicos totais agrupados no início do cromatograma com CAPE (éster fenitil do ácido cafeico) e Artepillin C, quantificados em ácido p-cumárico (Aguiar, 2012).

A ração foi fornecida duas vezes ao dia (às oito e às 16 horas). Água e sal mineral eram fornecidos à vontade. Na fase de adaptação, a quantidade de ração fornecida foi calculada de modo que permitisse $10 \%$ de sobras para mensuração do consumo voluntário. Durante a fase de coleta, a quantidade de alimento fornecida equivalia a $90 \%$ do consumo voluntário para evitar sobras e diminuir variações no consumo de matéria seca (MS).

Cada período experimental teve a duração total de 12 dias, sendo sete dias para adaptação dos animais às dietas e cinco dias para coleta de amostras, em um total de quatro períodos experimentais No penúltimo dia de cada período, o comportamento ingestivo foi observado por $24 \mathrm{~h}$ ininterruptas e, no último dia, foram coletadas amostras de sangue.
As dietas foram isoproteicas e isoenergéticas, ajustadas para ganho diário de $250 \mathrm{~g}$ (Nutrient..., 2007), e consistiam de feno de coast-cross e concentrado à base de farelo de soja e milho triturado, com relação de volumoso:concentrado de 40:60. A composição química dos alimentos utilizados e seu percentual na ração foram determinados no Laboratório de Nutrição Animal da Universidade Estadual de Londrina (Tab. 2).

Os teores de matéria seca (MS), matéria orgânica (MO), proteína bruta (PB) e extrato etéreo (EE) das amostras foram determinados de acordo com as metodologias descritas por Mizubuti et al. (2009), e os de FDN e FDA segundo Van Soest (1994) modificado por Detmann et al. (2012). 
Tabela 2. Composição química dos alimentos, composição química e percentual da dieta experimental

\begin{tabular}{|c|c|c|c|c|}
\hline & \multicolumn{4}{|c|}{ Ingredientes (\% MS) } \\
\hline & $\begin{array}{c}\text { Feno de } \\
\text { coast-cross }\end{array}$ & $\begin{array}{l}\text { Milho } \\
\text { moído }\end{array}$ & $\begin{array}{l}\text { Farelo } \\
\text { de soja }\end{array}$ & $\begin{array}{c}\text { Ração } \\
\text { total }\end{array}$ \\
\hline$\%$ do alimento na dieta ${ }^{4}$ & 40,00 & 51,57 & 8,43 & 100,00 \\
\hline \multirow[t]{2}{*}{ Composição das dietas } & \multicolumn{4}{|c|}{ Doses de LLOSC2 } \\
\hline & $0^{1}$ & $1^{2}$ & $2^{3}$ & $3^{4}$ \\
\hline Matéria seca (\%) & 76,45 & 87,40 & 80,43 & 82,44 \\
\hline Matéria orgânica $^{5}$ & 92,65 & 98,67 & 92,36 & 95,73 \\
\hline Proteína bruta ${ }^{5}$ & 13,49 & 8,33 & 54,92 & 14,33 \\
\hline Extrato etéreo $^{5}$ & 1,03 & 3,92 & 0,51 & 2,48 \\
\hline Fibra em detergente neutro ${ }^{5}$ & 79,91 & 14,90 & 27,39 & 41,96 \\
\hline Fibra em detergente ácido ${ }^{5}$ & 39,55 & 2,53 & 11,01 & 18,06 \\
\hline Carboidratos totais ${ }^{6}$ & 78,14 & 86,42 & 36,93 & 78,44 \\
\hline Carboidratos não fibrosos $^{6}$ & 9,06 & 38,60 & 30,84 & 50,13 \\
\hline Nutrientes digestíveis totais ${ }^{7}$ & 81,05 & 75,19 & 64,88 & 76,67 \\
\hline
\end{tabular}

Ração total $=$ relação volumoso:concentrado $40: 60 ;{ }^{1}$ dieta controle; ${ }^{2}$ dieta com uma dose do aditivo à base de extrato de própolis em pó LLOSC2 contendo $119,10 \mathrm{mg} \mathrm{g}^{-1}$ de compostos fenólicos; ${ }^{3}$ dieta com duas doses do aditivo à base de extrato de própolis em pó LLOSC2 contendo $238,20 \mathrm{mg} \mathrm{g}^{-1}$ de compostos fenólicos; ${ }^{4}$ dieta com três doses do aditivo à base de extrato de própolis em pó LLOSC2 contendo $357,30 \mathrm{mg} \mathrm{g}^{-1}$ de compostos fenólicos; ${ }^{5} \mathrm{em}$ porcentagem da matéria seca; ${ }^{6}$ calculados de acordo com Sniffen et al. (1992), em que CT(\%) = $100-(\% \mathrm{~PB}+\% \mathrm{EE}$ $+\% \mathrm{MM})$ e $\mathrm{CNF}=(100-\% \mathrm{FDNcp}-\% \mathrm{~PB}-\% \mathrm{EE}-\%$ cinzas $) ;{ }^{7}$ calculados de acordo com Weiss (1999), em que $\mathrm{NDT}(\%)=\mathrm{PBd}+\mathrm{FDNcpd}+\mathrm{CNFd}+2,25 \mathrm{x}$ EEd.

Para o cálculo da $\mathrm{MO}$, foi empregada a equação MO $(\%)=$ MS - MM, em que MM = matéria mineral, para carboidratos totais $(\mathrm{CT}), \mathrm{CT}(\%)=$ $100-(\% \mathrm{~PB}+\% \mathrm{EE}+\% \mathrm{MM})$, proposta por Sniffen et al. (1992), para $\mathrm{CNF}=(100-$ $\%$ FDNcp - \%PB - \%EE - \%cinzas), em que o FDNcp $=$ FDN corrigido para cinzas e proteína, e para NDT, NDT $(\%)=$ PBd + FDNcpd + CNFd $+2,25 \times$ EEd (WEISS, 1999).

No penúltimo dia de cada período experimental, os animais foram submetidos à observação visual para mensuração do comportamento ingestivo. As observações foram realizadas em quatro períodos de seis horas, perfazendo um total de $24 \mathrm{~h}$ de observação (das sete às $13 \mathrm{~h}$; das 13 às 19h, de 19 a uma hora e de 1 a sete horas). Durante os quatro períodos de observação, os comportamentos foram anotados com intervalos de cinco minutos entre cada uma delas, nos quais se mensurava o tempo despendido em alimentação, ruminação, ócio e ingestão de água (Johnson e Combs, 1991). O tempo gasto com alimentação visualmente foi definido como ato de morder, mastigar e engolir o feno e a ração concentrada. $\mathrm{O}$ ócio foi definido quando $\mathrm{o}$ animal não estava se alimentando, nem ruminando, nem ingerindo água.
A média do número de mastigações merícicas por bolo ruminal (ciclo) e o tempo despendido de mastigação merícica por bolo ruminal (ciclo) foram obtidos em quatro períodos de seis horas, distribuídos nos horários das sete às 13 horas, das 13 às 19 horas, de 19 a uma hora e de uma a sete horas, utilizando-se um cronômetro digital.

Durante as observações noturnas, o ambiente foi mantido sob iluminação artificial. Quatro dias antes da coleta de dados, as luzes eram mantidas acesas à noite para adaptação dos animais.

O sangue de cada animal foi coletado sempre no último dia de cada período, pela manhã, antes da alimentação. O método de coleta empregado foi a punção da veia jugular, por meio de tubos Vacutainer (BD - Becton, Dickinson and Co. Franklin Lakes, NJ, EUA) com capacidade para 4,0mL. Para cada animal foram coletadas três amostras de sangue: um tubo com EDTA, para determinação de hemograma, eritrograma, hematócrito e leucograma, um com heparina para mensurar glicose, ureia e creatinina e um sem anticoagulante para dosagem de imunoglobulinas e cortisol. O hemograma, o eritrograma, o hematócrito, o leucograma, a glicose, a ureia e a creatinina foram determinados no Laboratório de Patologia Clínica do Departamento de Medicina Veterinária Preventiva da Universidade Estadual 
de Londrina, por meio de kits comerciais. As análises de imunoglobulinas, utilizando-se o método de turbidimetria, e de cortisol, pelo método de quimioluminescência, foram feitas em laboratório comercial (Cetel - Laboratório Clínico).

Os dados foram submetidos à análise de variância, utilizando-se o SAS (2004), no procedimento ANOVA. As médias das dietas foram comparadas pelo teste de Tukey e considerou-se nível de $5 \%$ de probabilidade como significativo e até $20 \%$ como tendência.

\section{RESULTADOS E DISCUSSÃO}

Não houve efeito das dietas sobre o tempo despendido com alimentação, ruminação, ócio e ingestão de água $(\mathrm{P}>0,05)$. Contudo, houve uma tendência $(\mathrm{P}=0,14)$ nos animais que receberam uma dose de LLOSC2 a despender mais tempo em alimentação. Para o comportamento total, nas 24h, observou-se tendência em se aumentar o tempo gasto com alimentação em cordeiros que receberam dieta com três doses de LLOSC2 (Tab. 3).

Tabela 3. Comportamento ingestivo em cordeiros alimentados com dietas concentradas com a adição de diferentes doses de extrato de própolis em pó LLOSC2

\begin{tabular}{|c|c|c|c|c|c|c|c|}
\hline & \multicolumn{4}{|c|}{ Doses de LLOSC2 } & \multirow[b]{2}{*}{ Média } & \multirow[b]{2}{*}{$\mathrm{CV}(\%)^{5}$} & \multirow[b]{2}{*}{$\mathrm{P}^{6}$} \\
\hline & $0^{1}$ & $1^{2}$ & $2^{3}$ & $3^{4}$ & & & \\
\hline \multicolumn{8}{|c|}{$7-13 h$} \\
\hline Alimentação $^{7}$ & 67,50 & 57,50 & 73,75 & 61,25 & 65,00 & 13,51 & 0,14 \\
\hline Ruminação $^{7}$ & 72,50 & 81,25 & 83,75 & 71,25 & 77,19 & 45,37 & 0,94 \\
\hline Ócio $^{7}$ & 213,75 & 215,00 & 200,00 & 222,50 & 212,31 & 20,57 & 0,90 \\
\hline $\begin{array}{l}\text { Ingestão de } \\
\text { água }^{7}\end{array}$ & 8,75 & 2,50 & 5,00 & 3,75 & 5,00 & 104,08 & 0,42 \\
\hline \multicolumn{8}{|c|}{$13-19 \mathrm{~h}$} \\
\hline Alimentação $^{7}$ & 72,50 & 92,50 & 90,00 & 62,50 & 79,38 & 25,65 & 0,22 \\
\hline Ruminação $^{7}$ & 72,50 & 52,50 & 51,25 & 66,25 & 60,63 & 56,09 & 0,77 \\
\hline Ócio $^{7}$ & 208,75 & 220,00 & 212,50 & 230,00 & 217,81 & 16,43 & 0,84 \\
\hline $\begin{array}{l}\text { Ingestão de } \\
\text { água }^{7}\end{array}$ & 3,75 & 5,00 & 6,25 & 1,25 & 4,06 & 110,94 & 0,49 \\
\hline \multicolumn{8}{|c|}{$19-01 \mathrm{~h}$} \\
\hline Alimentação $^{7}$ & 73,75 & 53,75 & 57,50 & 41,25 & 56,56 & 37,74 & 0,29 \\
\hline Ruminação $^{7}$ & 56,25 & 62,50 & 62,50 & 77,50 & 64,69 & 29,83 & 0,50 \\
\hline Ócio ${ }^{7}$ & 227,50 & 251,25 & 236,25 & 240,00 & 238,75 & 10,47 & 0,62 \\
\hline $\begin{array}{l}\text { Ingestão de } \\
\text { água }^{7}\end{array}$ & 2,50 & 0,00 & 1,25 & 0,00 & 0,94 & 255,31 & 0,45 \\
\hline \multicolumn{8}{|c|}{$1-7 \mathrm{~h}$} \\
\hline Alimentação $^{7}$ & 8,75 & 12,50 & 6,25 & 10,00 & 9,38 & 53,33 & 0,42 \\
\hline Ruminação $^{7}$ & 168,75 & 167,50 & 175,00 & 170,00 & 170,31 & 18,77 & 0,98 \\
\hline Ócio $^{7}$ & 181,25 & 166,25 & 175,00 & 182,50 & 176,25 & 19,08 & 0,89 \\
\hline $\begin{array}{l}\text { Ingestão de } \\
\text { água }^{7}\end{array}$ & 2,50 & 1,25 & 2,50 & 1,25 & 1,88 & 172,13 & 0,89 \\
\hline \multicolumn{8}{|c|}{ Total } \\
\hline Alimentação $^{7}$ & 222,50 & 216,25 & 227,50 & 175,00 & 210,31 & 18,34 & 0,30 \\
\hline Ruminação $^{7}$ & 370,00 & 363,75 & 372,50 & 385,00 & 372,81 & 17,78 & 0,97 \\
\hline Ócio $^{7}$ & 831,25 & 852,50 & 823,75 & 875,00 & 845,63 & 9,28 & 0,79 \\
\hline $\begin{array}{l}\text { Ingestão de } \\
\text { água }^{7}\end{array}$ & 17,50 & 8,75 & 15,00 & 6,25 & 11,88 & 57,01 & 0,16 \\
\hline
\end{tabular}


Maiores tempos despendidos com a alimentação foram observados no período das 13 às 19 horas e das sete às 13 horas, respectivamente, e estes valores justificam-se pelo fato de as dietas terem sido fornecidas sempre às oito e às 16 horas. Já a intensidade de ruminação foi maior no período de uma a sete horas. Esses dados se assemelham aos descritos por Ítavo et al. (2008) e Faria et al. (2011).

A adição de duas doses de LLOSC2 proporcionou aumento $(\mathrm{P}<0,05)$ na duração do ciclo ruminativo no período das 13 às $19 \mathrm{~h}$ e uma tendência em aumentar o número de mastigações $(\mathrm{P}=0,19$; Tab. 4).

Tabela 4. Duração dos ciclos ruminativos e número de mastigações por ciclo em cordeiros alimentados com dietas concentradas com a adição de diferentes doses de extrato de própolis em pó LLOSC2

\begin{tabular}{|c|c|c|c|c|c|c|c|}
\hline & \multicolumn{4}{|c|}{ Doses de LLOSC2 } & \multirow[b]{2}{*}{ Média } & \multirow[b]{2}{*}{$\begin{array}{l}C V \\
(\%)^{5}\end{array}$} & \multirow[b]{2}{*}{$\mathrm{P}^{6}$} \\
\hline & $0^{1}$ & $1^{2}$ & $2^{3}$ & $3^{4}$ & & & \\
\hline \multicolumn{8}{|c|}{$7-13 h$} \\
\hline Duração do ciclo (segundos) & 40,05 & 48,60 & 46,70 & 46,85 & 45,55 & 13,20 & 1,57 \\
\hline $\mathrm{N}^{\mathrm{o}}$ de mastigações/ciclo & 60,45 & 68,85 & 65,20 & 65,05 & 64,89 & 10,96 & 0,48 \\
\hline \multicolumn{8}{|c|}{ 13-19h } \\
\hline Duração do ciclo (segundos) & $46,10 b$ & $46,15 b$ & $57,65 a$ & $45,10 \mathrm{~b}$ & 48,75 & 9,11 & 0,02 \\
\hline $\mathrm{N}^{\mathrm{o}}$ de mastigações/ciclo & 63,00 & 63,95 & 73,95 & 61,05 & 65,49 & 8,45 & 0,06 \\
\hline \multicolumn{8}{|c|}{ 19-1h } \\
\hline Duração do ciclo (segundos) & 44,45 & 40,60 & 45,15 & 44,60 & 43,70 & 10,95 & 0,56 \\
\hline $\mathrm{N}^{0}$ de mastigações/ciclo & 62,50 & 57,80 & 64,60 & 60,35 & 61,31 & 14,11 & 0,45 \\
\hline \multicolumn{8}{|c|}{$1-7 \mathrm{~h}$} \\
\hline Duração do ciclo (segundos) & 42,80 & 50,90 & 47,90 & 47,00 & 47,15 & 6,97 & 0,07 \\
\hline $\mathrm{N}^{\mathrm{o}}$ de mastigações/ciclo & $59,75 b$ & $69,75 \mathrm{a}$ & $63,50 \mathrm{ab}$ & $63,50 \mathrm{ab}$ & 63,87 & 4,65 & 0,02 \\
\hline \multicolumn{8}{|c|}{ TOTAL } \\
\hline Duração do ciclo (segundos) & 173,40 & 186,25 & 197,40 & 183,55 & 185,15 & 5,81 & 0,10 \\
\hline $\mathrm{N}^{0}$ de mastigações/ciclo & 245,70 & 260,35 & 267,25 & 245,70 & 255,56 & 5,34 & 0,19 \\
\hline $\begin{array}{l}{ }^{1} \text { Dieta controle; }{ }^{2} \text { dieta com uma } \\
\text { de compostos fenólicos; }{ }^{3} \text { dieta } \\
238,20 \mathrm{mg} \mathrm{g}^{-1} \text { de compostos fenó } \\
\text { contendo } 357,30 \mathrm{mg} \mathrm{g}^{-1} \text { de comp }\end{array}$ & $\begin{array}{l}\text { se do adi } \\
\mathrm{m} \text { duas } \mathrm{d} \\
\mathrm{cos} ;{ }^{4} \text { dieta }\end{array}$ & o à base $c$ & $\begin{array}{l}\text { àtrato de } \\
\text { à base do aditiv }\end{array}$ & $\begin{array}{l}\text { polis em } \mathrm{p} \\
\text { xtrato de } \mathrm{p} \\
\text { base de e }\end{array}$ & $\begin{array}{l}\text { LOSC2 c } \\
\text { polis em } \\
\text { ato de pró }\end{array}$ & $\begin{array}{l}\text { tendo } 1 \\
\text { LLOSC }\end{array}$ & $\begin{array}{l}0 \mathrm{mg} \mathrm{g}^{-1} \\
\text { ontendo } \\
\text { LOSC2 }\end{array}$ \\
\hline
\end{tabular}

Em bovinos a pasto, suplementados com 0,3 ou $0,6 \%$ do peso corporal (PC) com a adição ou não de extrato de própolis em pó LLOS $(2 \mathrm{~g} / \mathrm{kg}$ suplemento/dia), a inclusão desse extrato como aditivo proporcionou maior tempo despendido em ócio. Houve interação entre o nível de suplementação e a inclusão de LLOS para tempo em pastejo, sendo este menor com a adição de extrato de própolis associada à suplementação em $0,6 \%$ do PC (Silva et al., 2014).

No entanto, em outros estudos, não têm sido encontradas alterações comportamentais com o uso de extratos de própolis como aditivos. Em cordeiros que receberam dietas com relação volumoso:concentrado 50:50, com a adição de extrato líquido de própolis verde, marrom e monensina sódica na fase de terminação, não foram observadas alterações no tempo médio despendido com consumo, ruminação e ócio (Ítavo et al., 2008).

Faria et al. (2011), quando estudaram os efeitos da adição de uma ou duas doses de extrato de própolis LLOSC1 na dieta de bovinos inteiros em fase de terminação, não observaram efeitos da inclusão do aditivo sobre o comportamento animal.

No presente trabalho, a ausência de resultados positivos do extrato de própolis sobre os tempos despendidos em alimentação, ruminação, ócio e ingestão de água pode estar relacionada com o alto nível de concentrado na dieta, que favorece o desenvolvimento de bactérias ruminais Gram negativas, as quais degradam amido e proteína provenientes da dieta. Como os microrganismos ruminais Gram positivos são mais susceptíveis à ação do extrato de própolis, é possível que a 
dieta tenha alterado a população microbiana animal, levando a uma predominância de microrganismos ruminais Gram negativos, os quais são mais resistentes que os Gram positivos ao extrato de própolis.

Silva et al. (2014) avaliaram a influência de dois níveis de suplementação $(0,3$ e $0,6 \%$ do peso corporal) com ou sem a adição de dois gramas por quilograma de suplemento concentrado por dia de extrato de própolis (LLOS), em bovinos criados a pasto, sobre o comportamento ingestivo. Os pesquisadores constataram que, no teor de $0,3 \%$ do $\mathrm{PC}$, os animais que consumiram o LLOS apresentaram aumento na taxa e no número de bocados por dia. Todavia, o tempo de mastigação total, o número de mastigações merícicas por bolo e o tempo de bolo ruminado não sofreram efeitos do nível de suplementação nem da inclusão do extrato de própolis.

Para o período total de $24 \mathrm{~h}$, não houve efeito $(\mathrm{P}>0,05)$ dos extratos de própolis sobre a duração do ciclo e o número de mastigações.

Stradiotti Júnior et al. (2004), ao avaliarem, in vitro, a eficiência do extrato de própolis em inibir a produção de gases da fermentação de diversos alimentos, obtiveram uma maior taxa de digestão específica para carboidratos fibrosos e não fibrosos. Segundo Schofield et al. (1994), a taxa de digestão específica se correlaciona direta e positivamente com o crescimento microbiano. Portanto, pode-se dizer que o extrato de própolis pode estimular o crescimento microbiano, melhorando também a taxa de digestão. Com a elevação da taxa de degradação e/ou do fluxo da digesta, tem-se um aumento de consumo, uma vez que o limite físico de repleção ruminal não é atingido (Leão et al., 2005). Dessa forma, é possível que a dieta contendo duas doses de LLOSC2 tenha estimulado o crescimento bacteriano e a taxa de digestão, aumentando o consumo de alimentos e, consequentemente, a duração da ruminação.

Não houve efeito $(\mathrm{P}>0,05)$ da adição de LLOSC2 à dieta sobre os parâmetros hematológicos (eritrócitos, hemoglobinas, hematócrito) e os índices hematimétricos absolutos (volume corpuscular médio, hemoglobina corpuscular média e concentração de hemoglobina corpuscular média) (Tab. 5). Os valores médios encontrados para cada um dos parâmetros analisados se encontram dentro do padrão de normalidade para a espécie (Pugh e Baird, 2012; Weiss e Wardrop, 2010).

Os parâmetros bioquímicos avaliados não sofreram alterações $(\mathrm{P}>0,05)$ devido à inclusão dos extratos de própolis à dieta $(\mathrm{P}>0,05 ;$ Tab. 5$)$.

Houve uma tendência $(\mathrm{P}=0,19)$ à menor concentração de cortisol com a adição de três doses de LLOSC2 à dieta. Os níveis séricos médios de cortisol estão abaixo do descrito na literatura (Pugh e Baird, 2012), e isso pode ser um indicativo de que as condições experimentais não foram estressantes para os animais.

Quando comparada à dieta controle, a dieta com inclusão de uma dose de LLOSC2 proporcionou maior nível de cortisol. Durante o primeiro período experimental, o animal que estava recebendo a dieta com uma dose de LLOSC2 se encontrava na gaiola metabólica disposta mais próxima à porta, ocasionando, assim, maior estresse ao animal. $O$ nível sérico de cortisol do animal nesse período foi de $5,40 \mu \mathrm{g} / \mathrm{dL}$, o que contribuiu para o aumento do nível médio de cortisol na dieta em questão. No período experimental subsequente, o animal foi trocado de lugar e seu nível de cortisol foi de 3,45 e $0,83 \mu \mathrm{g} / \mathrm{dL}$ no segundo e terceiro períodos experimentais, respectivamente.

Em bovinos em terminação que receberam duas diferentes doses de extrato de própolis na dieta, foram encontrados níveis de cortisol semelhantes ao do presente estudo. A inclusão de LLOS também não afetou a concentração do hormônio (Faria et al., 2011).

A concentração de imunoglobulinas no soro sanguíneo não foi afetada pelo extrato de própolis ( $\mathrm{P}>0,05$; Tab. 4) e está de acordo com a quantidade média descrita para ovinos (Pugh e Baird, 2012). 
Tabela 5. Parâmetros sanguíneos em cordeiros alimentados com dietas concentradas com a adição de diferentes doses de extrato de própolis em pó LLOSC2

\begin{tabular}{|c|c|c|c|c|c|c|c|}
\hline \multirow[t]{2}{*}{ Parâmetro } & \multicolumn{4}{|c|}{ Doses de LLOSC2 } & \multirow{2}{*}{ Média } & \multirow[t]{2}{*}{$\mathrm{CV}^{5}$} & \multirow[t]{2}{*}{$\mathrm{P}^{6}$} \\
\hline & $0^{1}$ & $1^{2}$ & $2^{3}$ & $3^{4}$ & & & \\
\hline Cortisol ( $\mu \mathrm{g} / \mathrm{dL})$ & 1,93 & 2,53 & 1,98 & 1,00 & 1,86 & 46,49 & 0,19 \\
\hline Imunoglobulinas $(\mathrm{mg} / \mathrm{dL})$ & 2,13 & 2,13 & 2,38 & 2,00 & 2,16 & 11,10 & 0,26 \\
\hline Ureia $(\mathrm{mg} / \mathrm{dL})$ & 74,25 & 74,50 & 75,00 & 77,30 & 75,25 & 4,39 & 0,59 \\
\hline Creatinina $(\mathrm{mg} / \mathrm{dL})$ & 0,73 & 0,78 & 0,78 & 0,80 & 0,77 & 6,23 & 0,26 \\
\hline Glicose (mg/dL) & 28,00 & 32,50 & 30,75 & 33,00 & 31,06 & 13,62 & 0,41 \\
\hline Eritrócitos $\left(10^{6} / \mu \mathrm{L}\right)$ & 7,71 & 8,18 & 7,92 & 7,14 & 7,73 & 9,80 & 0,34 \\
\hline Hemoglobulinas (g/dL) & 10,55 & 11,31 & 10,48 & 10,38 & 10,68 & 6,19 & 0,27 \\
\hline Hematócrito (\%) & 31,83 & 33,48 & 31,08 & 31,35 & 31,93 & 5,61 & 0,32 \\
\hline $\operatorname{VCM}^{7}(\mathrm{fL})$ & 34,83 & 33,80 & 33,68 & 26,20 & 32,13 & 25,64 & 0,48 \\
\hline $\mathrm{HCM}^{8}(\mathrm{pg})$ & 11,35 & 11,30 & 11,40 & 11,25 & 11,33 & 3,00 & 0,93 \\
\hline $\mathrm{CHCM}^{9}(\mathrm{~g} / \mathrm{dL})$ & 32,88 & 33,65 & 33,80 & 34,55 & 33,72 & 4,14 & 0,47 \\
\hline Leucócitos (número/ $\mu \mathrm{L}$ ) & 6400 & 7538 & 8463 & 8550 & 7737,50 & 39,56 & 0,74 \\
\hline Segmentados (\%) & 28,00 & 29,50 & 25,00 & 27,00 & 27,38 & 15,25 & 0,53 \\
\hline Eosinófilos (\%) & 6,25 & 9,25 & 9,50 & 10,00 & 8,75 & 63,03 & 0,77 \\
\hline Linfócitos (\%) & 64,75 & 61,00 & 64,25 & 62,75 & 63,19 & 14,12 & 0,93 \\
\hline Monócitos (\%) & 1,00 & 0,25 & 1,25 & 0,25 & 0,69 & 131,11 & 0,36 \\
\hline
\end{tabular}

Ração total = relação volumoso:concentrado 40:60; ${ }^{1}$ dieta controle; ${ }^{2}$ dieta com uma dose do aditivo à base de extrato de própolis em pó LLOSC2 contendo $119,10 \mathrm{mg} \mathrm{g}^{-1}$ de compostos fenólicos; ${ }^{3}$ dieta com duas doses do aditivo à base de extrato de própolis em pó LLOSC2 contendo $238,20 \mathrm{mg} \mathrm{g}^{-1}$ de compostos fenólicos; ${ }^{4}$ dieta com três doses do aditivo à base de extrato de própolis em pó LLOSC2 contendo $357,30 \mathrm{mg} \mathrm{g}^{-1}$ de compostos fenólicos; ${ }^{5}$ coeficiente de variação; ${ }^{6}$ probabilidade; ${ }^{7}$ volume corpuscular médio; ${ }^{8}$ hemoglobina corpuscular média; ${ }^{9}$ concentração de hemoglobina corpuscular média.

De acordo com Yaghoubi et al. (2008), o extrato de própolis afeta a resposta humoral e pode aprimorar o crescimento de bezerros, sendo essa resposta dependente da idade do animal. Em seu estudo com bezerros de $7 \pm 2$ dias de idade, o nível de imunoglobulina $G$ foi menor nas três primeiras semanas do experimento com a adição de extratos de própolis com menor concentração de flavonoides $\left(7,3 \quad\right.$ x $\left.10^{5} \mathrm{~g} / \mathrm{kg} \quad \mathrm{PC}\right) \quad \mathrm{em}$ comparação ao extrato com maior concentração de flavonoides $\left(3,6 \times 10^{6} \mathrm{~g} / \mathrm{kg} \mathrm{PC}\right)$. Na oitava semana, os extratos com média dose $(7,3 \mathrm{x}$ $10^{4} \mathrm{~g} / \mathrm{kg}$ PC) e alta dose diminuíram a IgG sérica. $\mathrm{Na}$ sexta semana, os níveis séricos de IgM foram menores nos animais que receberam alta e média doses do extrato em relação à dieta controle.

Em ovelhas Santa Inês vazias e não lactentes mantidas a pasto e recebendo flushing alimentar após sincronização do cio, foram avaliadas as respostas hematológicas, bioquímicas e parasitárias da administração via oral de extrato de própolis vermelha ( $3 \mathrm{~g} / \mathrm{animal} / \mathrm{dia})$ durante e após o flushing. Os pesquisadores puderam concluir que o extrato de própolis ocasionou aumento na concentração de imunoglobulinas, tendo, assim, impacto positivo na resposta imune de ovelhas (Mosry et al, 2013).

No presente estudo, o extrato de própolis não exerceu efeito $(\mathrm{P}>0,05)$ sobre a contagem total de leucócitos e a porcentagem de segmentados, eosinófilos, linfócitos e monócitos (Tab. 4). As médias observadas foram semelhantes às descritas na literatura (Pugh e Baird, 2012; Weiss e Wardrop, 2010). Contudo, o número total de leucócitos foi superior aos valores encontrados em bovinos na fase de terminação com a adição de extrato de própolis LLOSC1 em relação à dieta controle, conforme relatos de Faria et al. (2011). Mosry et al. (2013) também observaram leucocitose em ovelhas que receberam extrato de própolis vermelha durante e após flushing alimentar posterior à sincronização de cio. Esse incremento na quantidade leucocitária pode estar relacionado à atividade imunoestimulante da própolis (Nassar et al., 2012), cuja alteração não foi observada neste ensaio. 
Como a composição do extrato é variável de acordo com a flora apícola e o processo de extração ao qual é submetido, é possível que o extrato utilizado neste estudo tivesse menor quantidade de compostos imunoestimulantes da própolis, como o Artepillin C.

Os parâmetros bioquímicos dos animais não foram afetados $(\mathrm{P}>0,05)$ pelo extrato de própolis. De acordo com Pugh e Baird (2012), as concentrações séricas de ureia e creatinina variaram de 20,93 a 67,23mg/dL (média: $41,8 \pm 10,3 \mathrm{mg} / \mathrm{dL}$ ) e de 1,01 a $1,97 \mathrm{mg} / \mathrm{dL}$ (média: $1,48 \pm 0,21 \mathrm{mg} / \mathrm{dL}$ ). As concentrações de ureia observadas neste estudo foram superiores e podem estar relacionadas ao maior aporte proteico. Já os valores de creatinina estão abaixo e indicam baixo catabolismo proteico.

Em média, os níveis séricos de glicose em ovinos devem estar entre 50 e $80 \mathrm{mg} / \mathrm{dL}$ (Pugh e Baird, 2012). Neste trabalho, obteve-se nível de glicose médio de $31,06 \mathrm{mg} / \mathrm{dL}$. Isto pode ser estar relacionado com o período de jejum dos animais, visto que o fornecimento de ração no período da tarde era realizado às $16 \mathrm{~h}$ e a coleta de sangue era feita às sete horas, antes do trato da manhã, totalizando $15 \mathrm{~h}$ de jejum.

\section{CONCLUSÕES}

A administração de extrato de própolis LLOSC2 à dieta de ovinos não afeta seu comportamento ingestivo, bem como os parâmetros hematológicos, bioquímicos e imunológicos estudados. Novas dosagens e teores alcoólicos podem ser testados, pois existem evidências de que o extrato de própolis também tem ação imunoestimulante.

\section{AGRADECIMENTOS}

Ao $\mathrm{CNPq}$, pelo fomento financeiro via edital Universal 14/2012.

\section{REFERÊNCIAS}

AGUIAR, S.C. Quantificação e caracterização dos compostos ativos da própolis e seus efeitos sobre a nutrição e qualidade do leite de vacas e cepas bacterianas do rúmen. 2012. 126f. Tese (Doutorado) - Universidade Estadual de Maringá, Maringá, SP
ANDREOTTI, R.; NICODEMO, M.L.F. Uso de Antimicrobianos na produção de bovinos e desenvolvimento de resistência. Campo Grande: EMBRAPA, 2004. (Documento 144). Disponível em:

$<$ http://www.cnpgc.embrapa.br/publicacoes/doc/ doc_pdf/Doc144.pdf $>$. Acessado em: 18 jan. 2014.

BRASIL. Ministério da Agricultura, pecuária e abastecimento. Instrução Normativa $n^{\circ} 13$ de 30 de nov. de 2004. Regulamento técnico sobre aditivos para produtos destinados à alimentação animal. Brasília, 2004. Disponível em: $<\mathrm{http}$ //sistemasweb.agricultura.gov.br/sislegis/ac tion/detalhaAto.do?method=visualizarAtoPortal Mapa\&chave $=133040692>$, acesso em: 29 jun. 2016.

DETMANN, E.; SOUZA, M.A.; VALADARES FILHO, S.C. Métodos para análise de alimentos. Visconde do Rio Branco: Universidade Federal de Viçosa, 2012. 214p.

FARIA, L.A.N.; BARBOSA, O.R.; ZEOULA, L.M. et al. Produto à base de própolis (LLOS) na dieta de bovinos inteiros confinados: comportamento animal e respostas sanguíneas. Acta Sci. Anim. Sci., v.33, p.79-85, 2011.

GUERCI, A. Métodos de análisis clínicos y su interpretación. Buenos Aires: El Ateneo, 1985. $513 \mathrm{p}$.

ÍTAVO, C.C.B.F.; MORAIS, M.G.; COSTA, C. et al. Padrão de comportamento de cordeiros submetidos a própolis verde e marrom e monensina sódica, na dieta na fase de terminação. In: CONGRESSO BRASILEIRO DE ZOOTECNIA, 21., 2008, João Pessoa. Anais... João Pessoa: ZOOTEC, 2008.

JOHNSON, T.R.; COMBS, D.K. Effects of prepartum diet, inert rumen bulk, and dietary polyethylene glycol on dry matter intake of lactating dairy cows. J. Dairy Sci., v.74, p.933944, 1991.

LEÃO, M.I.; VALADARES FILHO, S.C.; RENNÓ, L.N. et al. Consumos e digestibilidade totais e parciais de carboidratos totais, fibra em detergente neutro e carboidratos não fibrosos em novilhos submetidos a três níveis de ingestão e duas metodologias de digestas abomasal e omasal. Rev. Bras. Zootec., V.3, p.670-678, 2005. 
LEOPOLDINO, W.N.; LANA, R.P.; EIFERT. E.C. et al. Avaliação de ionóforos pela técnica da perda de potássio celular e produção de gases in vitro. Arq. Bras. Med. Vet. Zootec., v.59, p15161522, 2007.

MENDONÇA, S.S.; CAMPOS, J.M.S.; VALADARES FILHO, S.C. et al. Comportamento ingestivo de vacas leiteiras alimentadas com dietas à base de cana-de-açúcar ou silagem de milho. Rev. Bras. Zootec., v.33, p.723-728, 2004.

MIZUBUTI, I.Y.; PINTO, A.P.; PEREIRA, E.S.; RAMOS, B.M.O. Métodos laboratoriais de avaliação de alimentos. Londrina: EDUEL, 2009. 228p.

MORSY, A. S.; ABDALLA, A. L.; SOLTAN, Y. A. et al. Effect of brazilian red propolis administration on hematological, biochemical variables and parasitic response of Santa Inês ewes during and after flushing period. Trop. Anim. Health Prod. v.45, n.7, p.1609-1618, 2013.

NASSAR, S.A.; MOHAMED, A.H.; SOUFY, H. et al. Imunostimulant effect of Egyptian propolis in rabbits. Sci. World J., v.2012, [1-9], 2012.

NUTRIENT requirements of small ruminants. New York: National Academy of Sciences, 2007. 362 p.

PUGH, D.G.; BAIRD, A.N. Sheep and goat medicine. 2.ed. Maryland Heights: Elsevier Saunders. 2012. 640p.

SAS procedures guides. Version 6. Cary [ Estados Unidos]: SAS. Institute. 2004.

SCHOFIELD, P.; PITT, R.E.; PELL, A.N. Kinetics of fiber digestion from in vitro gas production. J. Anim. Sci., v.72, p.2980-2991, 1994.
SILVA, A.L.N.; SILVA, R.R.; SANTOS, G.J.P. et al. Correlation between ingestive behaviour, intake and performace of grazing cattle supplemented with or with out propolis extract (LLOS). J. Agric. Crop Res., v.2, p.1-10, 2014.

SMITH, G.S.; ALLEN, S.W.; QUANDT, J.E. Indicators postoperative pain cats and correlation with clinical criteria. Am. J. Vet. Res., v.57, p.1674-1678, 1996.

SNIFFEN, C.J.; O'CONNOR, J.D.; VAN SOEST, P.J. et al. A net carbohydrate and protein system for evaluating cattle diets; II. Carbohydrate and protein availability. J. Anim. Sci., v.70, p.3562-3577, 1992.

STRADIOTTI JÚNIOR, D.; QUEIROZ, A.C.; LANA, R.P. et al. Ação da própolis sobre a desaminação de aminoácidos e a fermentação ruminal. Rev. Bras. Zootec., v.33,

p.1086-1092, 2004.

VAN SOEST, P.J. Nutritional ecology of the ruminant. 2.ed. Ithaca: Cornell University Press, 1994. 476p.

WEISS, D.J., WARDROP. K.J. Schalm's veterinary hematology. 6.ed. Ames: WileyBlackwell, 2010. 1232p.

WEISS, W.P. Energy prediction equations for ruminant feeds. In: CORNELL NUTRITION CONFERENCE FOR FEED MANUFACTURERS, 61., 1999, Ithaca. Proceedings... Ithaca: Cornell University, 1999. p.176-185.

YAGHOUBI, S.M.; GHORBANI, G.R.; RAHMANI, H.R.; NIKKHAH, A. Growth, weaning performance and blood indicators of humoral immunity in Holstein calves fed supplemental flavonoids. J. Anim. Physiol. Anim. Nutr., v.92, p.456-462. 